Research Article

\title{
Workload Determines Workplace Stress among Health Professionals Working in Felege-Hiwot Referral Hospital, Bahir Dar, Northwest Ethiopia
}

\author{
Minyichil Birhanu (D), ${ }^{1}$ Berhane Gebrekidan, ${ }^{2}$ Getasew Tesefa, ${ }^{1}$ and Minale Tareke ${ }^{1}$ \\ ${ }^{1}$ Bahir Dar University, College of Medicine and Health Science, Bahir Bar, Ethiopia \\ ${ }^{2}$ Addis Ababa University, College of Health Sciences, School of Allied Health Sciences, Department of Nursing and Midwifery, \\ Addis Ababa, Ethiopia
}

Correspondence should be addressed to Minyichil Birhanu; mbym24@gmail.com

Received 13 July 2018; Accepted 16 October 2018; Published 26 November 2018

Academic Editor: Issam A. Al-Khatib

Copyright (c) 2018 Minyichil Birhanu et al. This is an open access article distributed under the Creative Commons Attribution License, which permits unrestricted use, distribution, and reproduction in any medium, provided the original work is properly cited.

\begin{abstract}
Background. Workplace stress occurs in all professionals but, in particular, health-care professionals are highly prone to workplace stress. Health-care professionals comprise an important group that can be impacted by workplace stress because of their unique work environment. The study was done to determine the level of workplace stress and its associated factors among health-care professionals in Felege-Hiwot Referral Hospital, Bahir Dar, Northwest Ethiopia. Methods. An institutional-based cross-sectional study was conducted among randomly selected health-care professionals in Felege-Hiwot Referral Hospital. Data were collected using a self-administered structured questionnaire by trained data collectors and the supervisor. The collected data were entered into EPI-info version 7 and exported to SPSS version 20 for analysis. Logistic regression was employed to assess the associations between dependent and explanatory variables. Results. This study revealed that prevalence of workplace stress was $68.2 \%$. Health professionals who work 50 hours and more per week and in night shift on sometimes base were more likely to develop workplace stress. Conclusion. The level of workplace stress among health professionals was found to be high. This was due to long working hours and working in night shift. Identifying the source of workplace stress among health professionals should be a great concern for health service managers and other stakeholders.
\end{abstract}

\section{Background}

Stress is a multidimensional concept which is originally derived from the Latin word, "stringere" which refers to draw tight, to describe hardships and/or affliction [1]. It often occurs when individuals' physical and emotion do not match or cannot handle their job demands, constraints, and/ or opportunities. "Stress may be established on two major types of stress: eustress (good stress) and distress." Individuals who experience eustress will be able to meet job demands, and this may help them to increase positive work life (e.g., satisfaction and positive moral values) [2].

On the contrary, "individuals who experience distress will not be able to fulfill job demands and this may motivate them to decrease quality of work life (e.g., dissatisfaction and negative moral values)" [3]. Consequently, it may decrease the ability of employees to control and manage physiological and psychological stresses, such as disturb their self-regulatory bodies, and they cannot meet their duties and responsibilities as a member of an organization [4]. Stress can be generally defined as undue, inappropriate, or exaggerated response to a situation [5]. Stress, particularly work stress, is said to cause fatigue, depression, and tension on people and employees in all types of businesses and industries [6].

Globally, work-related stress is estimated to affect one in three employees [7]. Workplace stress occurs in all professions, and in particular, health-care professionals comprise an important group that can be affected by workplace stress because of the nature of their work environment [8]. 
In health care, employee workplace stress can have a negative impact on the quality of patient care [9], and significant effect on the occurrence of health problems leading to change the current working place and job, quit the profession, and interrupt relationship with coworkers [10]. In general, different studies confirmed that work stress may lead to negative financial outcomes. Globally, the cost of work-related stress is estimated to be approximately $\$ 5.4$ billion each year, second to low back pain which is the most frequent occupational health problem [7].

In particular, stress in the nursing profession has been a major worldwide problem. A study among a large sample of Swedish nurses revealed that more than $80 \%$ of the nurses reported high job strain [11]. A study among personnel of a UK health authority reported that nurses were under the greatest pressure among all health-care personnel [12]. The study estimated that almost $10 \%$ of the gross national product in European countries is lost because of stressrelated absenteeism and turnover [13].

The magnitude of the problem was further emphasized in the report of the American Foundation for Suicide Prevention which claimed that, on the average, death by suicide is about $70 \%$ more likely among physicians than among other professionals and 250-400\% higher among female doctors. The major cause is stress and depression thereof [14]. It has been shown that health workers are highly prone to stress at work and experience more negative outcomes of stress than other professionals. Work stress in physicians will cause negative outcomes like adverse psychological well-being, job burnout, and significantly larger number of suicide attempts, alcohol dependency, and other psychosocial problems [15]. Stress may also harm professional effectiveness: it decreases attention [16], reduces concentration [17], impinges on decision-making skills [18], and reduces providers' abilities to establish strong relationships with patients [19]. Stress also may lead to increased burnout and is defined as a syndrome of depersonalization, emotional exhaustion, and a sense of low personal accomplishment [20].

According to the International Labour Organization, almost $10 \%$ of workplace accidents are related to stress seeing that the ability to effectively manage stress can help maintain organization harmony [21]. In the hospital, most of the employee stress is caused by work overload, repetitive duties, inadequate resources, physical environment (lighting, space, temperature, and disruption), psychological working environment (verbal abuse and inappropriate behaviours), working long hours, management issues, inadequate allocation of work, new technology, and others [22]. The study conducted to identify sources of stress in health-care personnel of each category showed that the prime sources of stress were underpayment, excessive workload, inadequate staff, and being involved in the emotional distress of patients [23].

Assessing workplace-related stress and its contributing factors among health professionals are important for the health professionals, patients, and organizations. Therefore, the aim of this study was to determine the level and factors of workplace stress among health professionals in
Felege-Hiwot Referral Hospital, Bahir Dar, Northwest Ethiopia.

\section{Methods}

An institutional-based cross-sectional study was conducted among health-care professionals in Felege-Hiwot Referral Hospital from March 1 to 20, 2015. Felege-Hiwot Referral Hospital is found in the capital city of Amhara Regional State, Bahir Dar, which is $565 \mathrm{~km}$ far away from the capital city of Ethiopia, Addis Ababa. It was established in 1963 as the district hospital, and it was upgraded to referral hospital in 1994. The hospital has Surgery, Medical, Pediatrics, Obstetrics and Gynecology, Psychiatry, Dental, and Orthopedics units with both outpatient and inpatient departments and follow-up departments. The hospital has a total of 415 health professionals. Sample size was determined by single population proportion formula, and it was 208 .

2.1. Sampling Procedure. All health professionals found in the hospital were stratified based on their profession (job). Stratified sampling technique was used to select the study units in each stratum. Based on the number of professionals found in each stratum, proportional allocation of the total sample size was carried out to attain the required sample size. Finally, the determined sample size for each stratum was recruited using simple random sampling technique.

2.2. Data Collection. Data were collected using a selfadministered questionnaire. The questionnaire consisted of sociodemographic information, working environment, and common outcomes of stress, causes of stress, and stresslevel measuring tool. The stress causes-related questionnaire contained 39 statements which were developed in a way that allows respondents to grade their responses on a five-point scale: strongly disagree $=1$, disagree $=2$, do not know $=3$, agree $=4$, and strongly agree $=5[10]$. The level of stress was measured using the Perceived Stress Scale (PSS) which was used by the World Health Organization (WHO) to examine personal stress. The questions were contextualized to workplace making participants to respond by correlating it to stress at workplace rather than stress at home. The scale was scored into 5 points like 0: never, 1: almost never, 2: sometimes, 3: fairly often, and 4: very often. Then, the scores for questions $4,5,7$, and 8 were reversed. Then, scores for each item were added to get a total score. Individual scores on the PSS can range from 0 to 40 with higher scores indicating higher perceived stress. Scores ranging from 0 to 13 were considered no stress while score 14 and above was considered as stress [24].

2.3. Data Quality Assurance. A pre-test was conducted using $5 \%$ of the sample among health professionals in the Bahir Dar health centre to assess instrument simplicity, flow, and consistency. Some modifications were made based on the result from the pre-test. Data were collected by one-day trained data collectors and a supervisor. Data completeness 
and consistency were checked by the supervisor and investigators.

2.4. Data Processing and Analysis. Data were entered and cleaned using Epi-Info version 7 and exported to Statistical Package for Social Science (SPSS) version 20 for analysis. Descriptive analysis was used to present results. Binary logistic regression was used to assess associations between dependent and independent variables. The degree of associations was interpreted using odds ratio (OR) and 95\% confidence interval (CI) at $0.05 p$ value.

2.5. Ethical Consideration. Ethical clearance was obtained from Addis Ababa University, College of Health Sciences; a research review committee before data collection. Support letter was obtained from Felege-Hiwot Referral Hospital officials and concerned stakeholder. Oral consent was obtained from each study participants during data collection. The right was given to study participants to refuse, stop, or withdraw from the interview at any time. Confidentiality was maintained throughout the study.

\section{Result}

3.1. Sociodemographic Characteristics. Of the 208 sample health professionals, data were collected from 198 health professionals with a response rate of $95 \%$. A majority of the participants (55.1\%) were males. The ages of the respondents ranged from 23 to 59 years with a mean age of $31.33 \pm 7$ years, and 111 (56.1\%) were married. Most respondents (89 $(44.9 \%))$ have Bachelor of Science degree (Table 1).

3.2. Working Units. Among respondents who work in inpatient departments, the majority $(30(26.78 \%))$ were from the surgical ward (Figure 1); and from study participants who work in the outpatient department, most (39.6\%) were from the medical OPD (Figure 2).

3.3. Job Characteristics. Most (85 (42.9\%)) health professionals have high workload ( $>50 \mathrm{hr} /$ week). A majority $(79.3 \%)$ of respondents worked in night shift sometimes. One hundred eight (54.5\%) health professionals work on night and weekend call duties in addition to their daily work on sometimes base. One hundred fifty-six (78.8\%) health professionals believed that there is no adequate staff to do the job properly. The result showed that $164(82.2 \%)$ of respondents did not spend enough time with their family, and $125(63.1 \%)$ of respondents had close friends or family in their workplace. A majority $(152(76.8 \%))$ of health professionals did not get extracurricular activities from their hospital administration that would decrease the stress level in their workplace and did not spend enough time with their family $162(82.2 \%)$ (Table 2 ).

3.4. Stress Level. The PSS score for the study participants ranged from 3 to 28 with a mean of $15.97 \pm 5.25$. Using the
PSS score of 14 and above, the prevalence of workplace stress in this study was $68.2 \%$ (95\% CI: 62.8-73.2).

The result revealed that the mean scores of the workplace stress level among anaesthetists, pharmacists, midwiferies, radiographers, nurses, laboratory technicians/technologists, psychiatrists/sanitarian/health educators, physicians, and residents were 18.9, 18.1, 17.8, 17.4, 16.9, 15.7, 15.2, 12.3, and 11.5, respectively (Figure 3 ).

3.5. Anticipated Outcome of Workplace Stress. Nearly onethird of health professionals planned to change the current hospital, change the job (61 (25\%)), and plan to quit the practice (42 (17\%)); 33 (14\%) had bad relationship with coworkers, and 26 (14\%) developed some health problems as a result of workplace stress (Figure 4).

3.6. Factors Associated with Workplace Stress among Health Professionals. All independent variables were checked for association with the dependent variable by binary logistic regression. On bivariate analysis, the factors $p$ value less than 0.2 were age, educational level, job, monthly income, workload, working in night shift, working in weekend, demand conflict on time, spend enough time, and knowing whom to approach where there is stress.

In order to control the possible confounder's effect, $p$ value of less than 0.2 in bivariate analysis was included in the multivariate analysis. The multivariate analysis indicated that workload and working in night shift were significantly associated with stress with a $p$ value less than 0.05 .

The result revealed that health professionals who work $>50 \mathrm{hr} /$ week were ten times more stressed than those who work $40 \mathrm{hr} /$ week (AOR: 9.630, 95\% CI: 2.410-38.460). Respondents who work 41-50 hours per week were 6 times more stressed than those who work 40 hours per week (AOR: 5.98, 95\% CI: 9.935-35.997). Study participants who work in night shifts on sometimes base were highly stressed than those who never work in night shifts (AOR: 3.6, 95\% CI: 1.009-13.286) (Table 3).

\section{Discussion}

In this study, the prevalence of workplace stress was $68.2 \%$ which is in line with the study in Saudi Arabia (66.2\%) [25] and India (73.5\%) [26]. However, in the present study, the prevalence was higher than results reported from Dutch (55\%) [27], Belgium (40.4\%) [28], Iran (34.9\%) [29], and other parts of Ethiopia (37.8\%) [7]). The possible reasons for the difference might be due to differences in tools used, study participants (previous studies included only one professional group), and relative small sample size in the current study.

Similar to the finding from the study done in Saudi [10], there was no statistically significant difference between sex and marital status and workplace stress in the current study. However, reports from Lodz, Poland [30], and other parts of Ethiopia (AOR: 2.47, 95\% CI: 1.28, 4.77) [7]) pointed that female health professionals were more likely to have stress than males. Furthermore, the study in other parts of Ethiopia 
TABLE 1: Sociodemographic variables and stress levels among health-care professionals in Felege-Hiwot Referral Hospital, Bahir Dar, Northwest, Ethiopia, 2015.

\begin{tabular}{|c|c|c|c|}
\hline \multirow{2}{*}{ Variable } & \multirow{2}{*}{ Overall $N(\%)$} & \multicolumn{2}{|c|}{ Stressed } \\
\hline & & Yes $N(\%)$ & No $N(\%)$ \\
\hline \multicolumn{4}{|l|}{ Sex } \\
\hline Male & $109(55.1)$ & $74(67.9)$ & $35(32.1)$ \\
\hline Female & $89(44.9)$ & $61(68.5)$ & $28(31.5)$ \\
\hline \multicolumn{4}{|l|}{ Age } \\
\hline$\leq 25$ & $29(14.6)$ & $21(72.4)$ & $8(27.6)$ \\
\hline $26-30$ & $97(49)$ & $67(69.1)$ & $30(30.9)$ \\
\hline $31-35$ & $30(15.2)$ & $15(50.0)$ & $15(50.0)$ \\
\hline $36-40$ & $21(10.6)$ & $17(81.0)$ & $4(19.0)$ \\
\hline $41-45$ & $11(5.6)$ & $9(81.8)$ & $2(18.2)$ \\
\hline$\geq 46$ & $10(5.1)$ & $6(60.0)$ & $4(40.0)$ \\
\hline \multicolumn{4}{|l|}{ Marital status } \\
\hline Married & $111(56.1)$ & $76(68.5)$ & $35(31.5)$ \\
\hline Divorced & $5(2.5)$ & $4(80.0)$ & $1(20.0)$ \\
\hline Single & $82(41.4)$ & $55(67.1)$ & 27 (32.9) \\
\hline \multicolumn{4}{|l|}{ Job } \\
\hline Physician & $45(22.7)$ & $15(33.3)$ & $30(66.7)$ \\
\hline Nurse/midwifery/anaesthetist/radiographer & $114(57.6)$ & $93(81.6)$ & $21(18.4)$ \\
\hline Others & $39(19.7)$ & $27(69.2)$ & $12(30.8)$ \\
\hline \multicolumn{4}{|l|}{ Educational level } \\
\hline Diploma & $55(27.8)$ & $49(89.1)$ & $6(10.9)$ \\
\hline Bachelor's degree & $89(44.9)$ & $67(75.3)$ & $22(24.7)$ \\
\hline Doctorate degree & $39(19.7)$ & $11(28.2)$ & $28(71.8)$ \\
\hline Master's degree & $11(5.6)$ & $6(54.5)$ & $5(45.5)$ \\
\hline Postdoctoral degree & $4(2)$ & $2(50.0)$ & $2(50.0)$ \\
\hline \multicolumn{4}{|l|}{ Religion } \\
\hline Orthodox tewahedo & $171(86.4)$ & $117(68.4)$ & $54(31.6)$ \\
\hline Muslim & $15(7.6)$ & $9(60.0)$ & $6(40.0)$ \\
\hline Protestant & $12(6.1)$ & $9(75.0)$ & $3(25.0)$ \\
\hline \multicolumn{4}{|l|}{ Working unit } \\
\hline \multicolumn{4}{|l|}{ Outpatient department } \\
\hline Surgical OPD & $28(14.1)$ & $16(57.1)$ & $12(42.9)$ \\
\hline Psychiatrics OPD & $3(1.5)$ & $1(33.3)$ & $2(66.7)$ \\
\hline Obstetrics and gynecology OPD & $12(6.1)$ & $7(58.3)$ & $5(41.7)$ \\
\hline Pediatrics OPD & $7(3.5)$ & $4(57.1)$ & $3(42.9)$ \\
\hline Accident and casualty department & $7(3.5)$ & $5(71.4)$ & $2(28.6)$ \\
\hline Medical OPD & $37(18.7)$ & $23(62.2)$ & $14(37.8)$ \\
\hline \multicolumn{4}{|l|}{ Inpatient department } \\
\hline Surgical ward & $30(15.2)$ & $19(63.3)$ & $11(36.7)$ \\
\hline Medical ward & $21(10.6)$ & $12(57.1)$ & $9(42.9)$ \\
\hline OR & $17(8.6)$ & $11(64.7)$ & $6(35.3)$ \\
\hline Psychiatry ward & $2(1)$ & $1(50.0)$ & $1(50.0)$ \\
\hline Obstetrics and gynecology ward & $25(12.6)$ & $17(68.0)$ & $8(32.0)$ \\
\hline Pediatrics ward & $6(3)$ & $5(83.3)$ & $1(16.7)$ \\
\hline ICU & $5(2.5)$ & $3(60.0)$ & $2(40.0)$ \\
\hline Other & $6(3)$ & $4(66.7)$ & $2(33.3)$ \\
\hline \multicolumn{4}{|l|}{ Work experience } \\
\hline $1-7$ years & $117(59.1)$ & $79(67.5)$ & $38(32.5)$ \\
\hline $8-14$ years & $53(26.8)$ & $34(64.2)$ & $19(35.8)$ \\
\hline $15-21$ years & $14(7.1)$ & $13(92.9)$ & $1(7.1)$ \\
\hline $22-28$ years & $9(4.5)$ & $6(66.7)$ & $3(33.3)$ \\
\hline $28-35$ years & $5(2.5)$ & $3(60.0)$ & $2(40.0)$ \\
\hline \multicolumn{4}{|l|}{ Monthly income } \\
\hline$<5000$ birr & $137(69.2)$ & $121(88.3)$ & $16(11.7)$ \\
\hline 5000-10000 birr & $54(27.3)$ & $12(22.2)$ & $42(77.8)$ \\
\hline$>10000$ birr & $7(3.5)$ & $2(28.6)$ & $5(71.4)$ \\
\hline
\end{tabular}




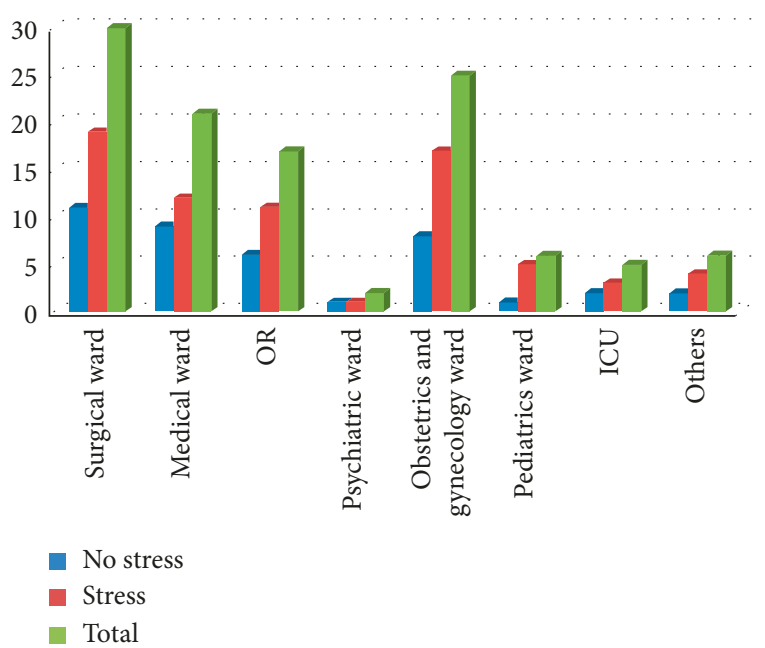

Figure 1: Distribution of health professionals by their inpatient working unit and stress level in Felege-Hiwot Referral Hospital, Bahir Dar, Northwest Ethiopia, 2015.

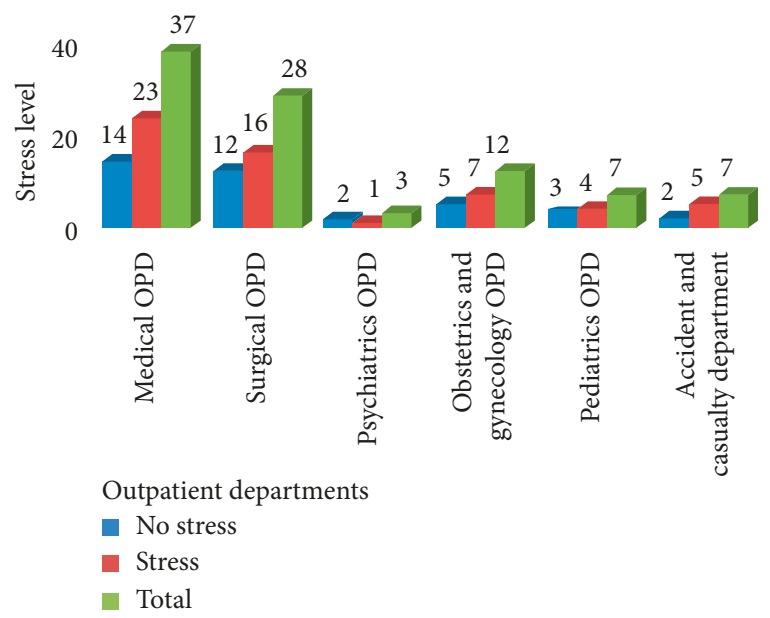

FIGURE 2: Distribution of health professionals by their outpatient department working unit and stress level in Felege-Hiwot Referral Hospital, Bahir Dar, Northwest Ethiopia, 2015.

showed that widowed and divorced nurses were 10 times more likely to experience workplace stress than married nurses (AOR: 10.11, 95\% CI: 4.56-15.17) [7]. These differences might be due to difference in study participants showing that these two studies included only nurses, but the current study included all health professionals.

In this study, health professionals' educational level did not significantly influence the level of workplace stress, which is consistent with the study in Saudi Arabia [25], Iceland [31], and other parts of Ethiopia [7]. In contrast, the result from Saudi brought out that the work-stress level was low among those holding postgraduate degrees [10]. Although the difference was not statistically significant, the present study reported that workplace stress was higher among anaesthetists (mean stress level 18.9) and lower among residents (mean stress level 11.5). Nevertheless, work stress was higher among doctors (stress level $=4.04$ ) and lower among hospital administrators (stress level $=3.69$ ) in Saudi Arabia [10]. The reasons for the difference might be difference in sample size and tools used.

The current study revealed that there was no significant association between monthly income and stress level among health professionals. But, the study in Germany and Austria among physicians, radiographers, nurses, and medical physicists working in radiotherapy showed that the greatest stress factors for nurses were "underpayment" [32]. This difference might be due to differences in tools used. The study in Saudi Arabia showed that those who work more than 50 hours per week were more stressed (79.4\%; $p=0.001$ ) [25]. Similarly, this study disclosed that those who work more than 50 hours per week were more stressed than those who work 40 hours per week (AOR: 9.6, 95\% CI: 2.410-38.46); and those who work 40-50 hours per week were six times more stressed than those who work 40 hours per week (AOR: 5.98, 95\% CI: 9.935-35.997). The current study showed that those who work in night shifts on sometimes base were more stressed than who never work in night shifts (AOR: 3.66, 95\% CI: 1.009-13.286). It coincides with the study in Saudi Arabia reported that those who always worked in night shifts were $84.0 \%$ more stressed $(p<0.001)$ compared to those who never or sometimes worked [25] which is supported by the findings from Germany and Austria indicating that the main source of workplace distress was working in night shifts [32].

In the current study, frequently stated sources of workplace stress by physicians were "Job-requirement is more than my ability" (mean score 3.72), "work shifts are changing frequently" (mean score 3.72), "working with opposite sex" (mean score 3.69), "feeling isolated" (mean score 3.66), and "hospital objectives do not match mine" (mean score 3.66). But, the study in Germany and Austria showed that the four greatest sources of a physician's job stress were "too much office work" (mean score 3.4), "time pressure" (mean score 3.36), "ill-defined responsibilities" (mean score 3.13), and "breaking off the conversation with the patient" (mean score 3.10). The variation with the current study might be due to differences in setting and sample size.

Nurses frequently stated "working with opposite sex" (mean score 3.35), "feeling isolated" (mean score 3.31), "lack of stability at home" (mean score 3.30), and "supervising the work of other people" (mean score 3.29) as the source of workplace stress. However, the study in Germany and Austria showed that "permanent ringing of telephone" (mean score 3.53), "against the conviction patients were kept alive by all means" (mean score 3.22), "underpayment" (mean score 3.21), and "time pressure" (mean score 3.11) were sources of workplace stress for nurses. The variation with the current study might be due to differences in setting and sample size.

For radiographers, frequently stated sources of workplace stress were "working with opposite sex," "being not respected," "job-requirement is more than my ability," "lack of stability at home," "unclear promotion requirements," and "no participation in department's decision making" with respective mean scores of 4.00, 3.86, 3.86, 3.71, 3.71, and 
TABLE 2: Job characteristics and level of workplace stress among health-care professionals in Felege-Hiwot Referral Hospital, Bahir Dar, Northwest Ethiopia, 2015.

\begin{tabular}{|c|c|c|c|}
\hline \multirow{2}{*}{ Job characteristics } & \multirow{2}{*}{ Overall $N(\%)$} & \multicolumn{2}{|c|}{ Stressed } \\
\hline & & Yes $N(\%)$ & No $N(\%)$ \\
\hline \multicolumn{4}{|l|}{ Workload } \\
\hline $40 \mathrm{hr} /$ week & $55(27.8)$ & $28(50.9)$ & $27(49.1)$ \\
\hline $41-50 \mathrm{hr} /$ week & $58(29.3)$ & $51(87.9)$ & $7(12.1)$ \\
\hline$>50 \mathrm{hr} /$ week & $85(42.9)$ & $56(65.9)$ & $29(34.1)$ \\
\hline \multicolumn{4}{|c|}{ Working in night shift } \\
\hline All the time & $14(7.1)$ & $10(71.4)$ & $4(28.6)$ \\
\hline Sometimes & $157(79.3)$ & $114(72.6)$ & $43(27.4)$ \\
\hline Not at all & $27(13.6)$ & $11(40.7)$ & $16(59.3)$ \\
\hline \multicolumn{4}{|c|}{ Working on weekends } \\
\hline All the time & $26(13.1)$ & $20(76.9)$ & $6(23.1)$ \\
\hline Sometimes & $149(75.3)$ & $105(70.5)$ & $44(29.5)$ \\
\hline Not at all & $23(11.6)$ & $10(43.5)$ & $13(56.5)$ \\
\hline \multicolumn{4}{|c|}{$\begin{array}{l}\text { Working on night/weekend call duties in addition to } \\
\text { daily work }\end{array}$} \\
\hline All the time & $13(6.6)$ & $10(76.9)$ & $3(23.1)$ \\
\hline Sometimes & $108(54.5)$ & $74(68.5)$ & $34(31.5)$ \\
\hline Not at all & $77(38.9)$ & $51(66.2)$ & $26(33.8)$ \\
\hline \multicolumn{4}{|c|}{ Getting free time compensation } \\
\hline All the time & $8(4.0)$ & $5(62.5)$ & $3(37.5)$ \\
\hline Sometimes & $96(48.5)$ & $70(72.9)$ & $26(27.1)$ \\
\hline Not at all & $94(47.5)$ & $60(63.8)$ & $34(36.2)$ \\
\hline \multicolumn{4}{|c|}{ Demand conflict on time } \\
\hline All the time & $27(13.6)$ & $21(77.8)$ & $6(22.2)$ \\
\hline Sometimes & $120(60.6)$ & $84(70.0)$ & $36(30.0)$ \\
\hline Not at all & $51(25.8)$ & $30(58.8)$ & $21(41.2)$ \\
\hline \multicolumn{4}{|c|}{ Workplace offer support for stress relief } \\
\hline All the time & $13(6.6)$ & $12(92.3)$ & $1(7.7)$ \\
\hline Sometimes & $48(24.2)$ & $33(68.8)$ & $15(31.2)$ \\
\hline Not at all & $137(69.2)$ & $90(65.7)$ & $47(34.3)$ \\
\hline \multicolumn{4}{|c|}{$\begin{array}{l}\text { Believe that there is inadequate staffing to do the job } \\
\text { properly }\end{array}$} \\
\hline Yes & $156(78.8)$ & $108(69.2)$ & $48(30.8)$ \\
\hline No & $42(21.2)$ & $27(64.3)$ & $15(35.7)$ \\
\hline \multicolumn{4}{|c|}{ Spend enough time with family } \\
\hline No & $164(82.2)$ & $119(72.6)$ & $45(27.4)$ \\
\hline Yes & $34(17.2)$ & $16(47.1)$ & $18(52.9)$ \\
\hline \multicolumn{4}{|c|}{ Having close friends/family in workplace } \\
\hline No & $73(36.9)$ & $53(72.6)$ & $20(27.4)$ \\
\hline Yes & $125(63.1)$ & $82(65.6)$ & $43(34.4)$ \\
\hline \multicolumn{4}{|c|}{$\begin{array}{l}\text { Workplace provide extracurricular activities that } \\
\text { would decreased stress level }\end{array}$} \\
\hline No & $152(76.8)$ & $101(66.4)$ & $51(33.6)$ \\
\hline Yes & $46(23.2)$ & $34(73.9)$ & $12(26.1)$ \\
\hline \multicolumn{4}{|c|}{ Know whom to approach when stressed } \\
\hline No & $94(47.5)$ & $69(73.4)$ & $25(26.6)$ \\
\hline Yes & $104(52.5)$ & $66(63.5)$ & $38(36.5)$ \\
\hline
\end{tabular}

3.71. On the other hand, in the study in Germany and Austria, "against the conviction patients were kept alive by all means" (mean score 2.88), "stress due to patient's disease progression" (mean score 2.79), "high physical workload" (mean score 2.76), and "patients suffering of my therapy" (mean score 2.74) were the main sources of radiographers' workplace stress [32]. The variation with the current study might be due to differences in setting and sample size.

The strength of this study is this is the first of its kind in Ethiopia that determines workplace stress and associated factors among different health professionals. However, similar to other studies, this study has limitations of selfreported data bias.

\section{Conclusion}

A majority of health professionals significantly experienced workplace stress. Workload and working in night shift were significantly associated with workplace stress. Health policy makers and hospital managers should 


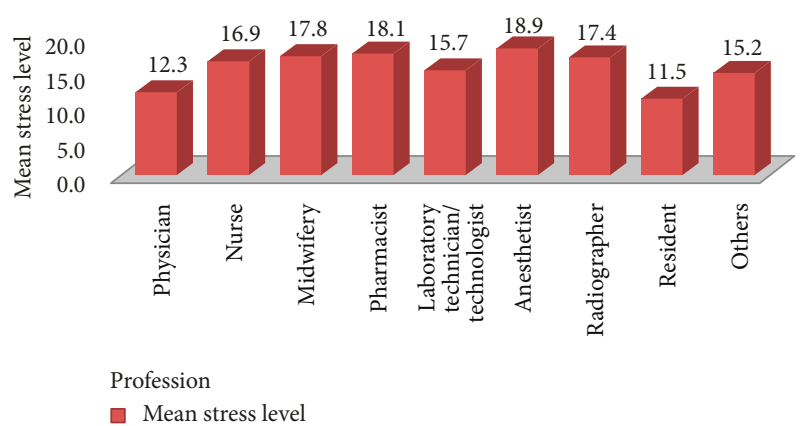

Figure 3: Comparison of workplace stress level among different professional groups in Felege-Hiwot Referral Hospital, Bahir Dar, Northwest Ethiopia, 2015.

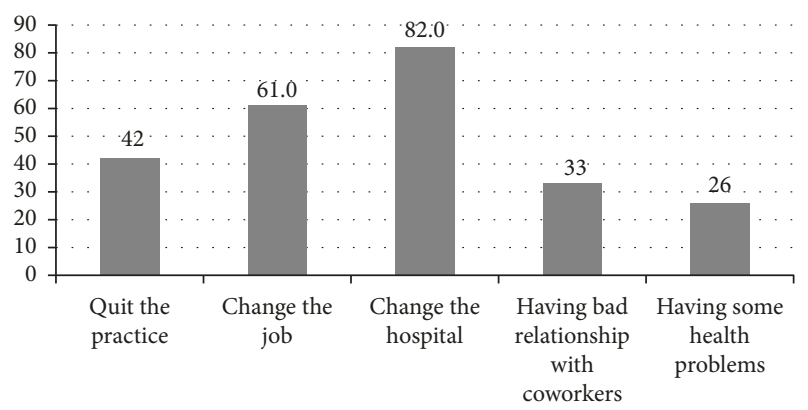

Figure 4: Anticipated results of workplace stress among health professionals in Felege-Hiwot Referral Hospital, Bahir Dar, Northwest Ethiopia, 2015.

TABle 3: Results of logistic analysis between dependent and independent variables among health professionals in Felege-Hiwot Referral Hospital, Bahir Dar, Northwest Ethiopia, 2015.

\begin{tabular}{|c|c|c|c|c|c|}
\hline \multirow[b]{2}{*}{ Variable } & \multicolumn{2}{|c|}{ Stressed } & \multicolumn{2}{|c|}{$95 \% \mathrm{CI}$} & \multirow[b]{2}{*}{$\begin{array}{c}p \\
\text { value }\end{array}$} \\
\hline & $\begin{array}{c}\text { Yes } \\
N(\%)\end{array}$ & $\begin{array}{c}\text { No } \\
N(\%)\end{array}$ & COR & AOR & \\
\hline $\begin{array}{l}\text { Workload } \\
>50 \mathrm{hr} / \\
\text { week }\end{array}$ & $\begin{array}{c}56 \\
(65.9)\end{array}$ & $\begin{array}{c}29 \\
(34.1)\end{array}$ & $\begin{array}{c}1.86 \\
(0.93-3.72)\end{array}$ & $\begin{array}{c}9.63 \\
(2.41-38.46)\end{array}$ & 0.001 \\
\hline $\begin{array}{l}41-50 \mathrm{hr} / \\
\text { week }\end{array}$ & $\begin{array}{c}51 \\
(87.9)\end{array}$ & $\begin{array}{c}7 \\
(12.1)\end{array}$ & $\begin{array}{c}7.03 \\
(2.71-18.17)\end{array}$ & $\begin{array}{c}5.98 \\
(9.93-35.99)\end{array}$ & 0.008 \\
\hline $40 \mathrm{hr} /$ week & $\begin{array}{c}28 \\
(50.9) \\
\end{array}$ & $\begin{array}{c}27 \\
(49.1) \\
\end{array}$ & 1 & 1 & \\
\hline \multicolumn{6}{|c|}{ Working in night shift } \\
\hline $\begin{array}{l}\text { All the } \\
\text { time }\end{array}$ & $\begin{array}{c}10 \\
(71.4)\end{array}$ & $\begin{array}{c}4 \\
(28.6)\end{array}$ & $\begin{array}{c}3.64 \\
(0.90-14.60)\end{array}$ & $\begin{array}{c}6.65 \\
(0.65-67.73)\end{array}$ & 0.11 \\
\hline Sometimes & $\begin{array}{c}114 \\
(72.6)\end{array}$ & $\begin{array}{c}43 \\
(27.4)\end{array}$ & $\begin{array}{c}3.85 \\
(1.65-8.96)\end{array}$ & $\begin{array}{c}3.66 \\
(1.00-13.28)\end{array}$ & 0.04 \\
\hline Not at all & $\begin{array}{c}11 \\
(40.7)\end{array}$ & $\begin{array}{c}16 \\
(59.3)\end{array}$ & 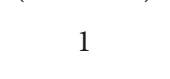 & $x^{2}+2+5$ & \\
\hline
\end{tabular}

Note. COR: crude odds ratio, AOR: adjusted odds ratio, CI: confidence interval.

identify sources of workplace stress and should be concerned about workplace stress. Further large-scale study should be done in different parts of the country to provide strong evidence regarding the determinants of workplace stress among health professionals.

\section{Acronyms}

AOR: Adjusted odds ratio

CCU: Coronary care unit

CI: $\quad$ Confidence interval

DEGRO: German Society of Radiation Oncology

FBAS: Stress questionnaire of physicians and nurses

HSE: Health safety executive

ICU: Intensive care unit

MOH: $\quad$ Ministry of Health

MS: $\quad$ Management standard

OR: $\quad$ Odds ratio

PSS: $\quad$ Perceived stress scale

SSO: $\quad$ Social security organization

UK: $\quad$ United Kingdom

WHO: World Health Organization.

\section{Data Availability}

The data used to support the findings of this study are available from the corresponding author upon request.

\section{Ethical Approval}

Ethical clearance was obtained from Addis Ababa University, College of Health Sciences.

\section{Disclosure}

The views presented in the article are of the authors, and it does not necessarily express the views of the funding organization. The Addis Ababa University was not involved in the design of the study, data collection, analysis, and interpretation.

\section{Conflicts of Interest}

The authors declare that there are no conflicts of interest.

\section{Authors' Contributions}

All authors contributed to the design of this study. MB conceived and designed the study; collected, analyzed, and interpreted data; and drafted the manuscript for important intellectual content. All authors reviewed and revised the draft further and approved the final version for submission.

\section{Acknowledgments}

We would like to say thanks to Addis Ababa University and Bahir Dar University for giving this golden opportunity for doing this thesis and for their financial support. Last but not the least, we would like to thank our study participants. This study was funded by Addis Ababa University.

\section{References}

[1] C. L. Cooper and S. Cartwright, "An intervention strategy for workplace stress," Journal of Psychosomatic Research, vol. 43, no. 1, pp. 7-16, 1997. 
[2] A. Ismail, A. Yao, E. Yeo, K. Lai-Kuan, and J. Soon-Yew, "Occupational stress features, emotional intelligence and job satisfaction: an empirical study in private institutions of higher learning," Scientific Journal of Management Science, vol. 16, no. 5, pp. 5-33, 2010.

[3] A. Ismail, A. Yao, and N. K. Y. Yunus, "Relationship between occupational stress and job satisfaction: an empirical study in Malaysia," Romanian Economic Journal, vol. 12, no. 34, pp. 3-30, 2009.

[4] H. D. Critchley, P. Rotshtein, Y. Nagai, J. O’Doherty, C. J. Mathias, and R. J. Dolan, "Activity in the human brain predicting differential heart rate responses to emotional facial expressions," NeuroImage, vol. 24, no. 3, pp. 751-762, 2005.

[5] B. Sibbald, C. Bojke, and H. Gravelle, "National survey of job satisfaction and retirement intentions among general practitioners in England," BMJ, vol. 326, no. 7379, p. 22, 2003.

[6] A. Usman, Z. Ahmed, I. Ahmed, and Z. Akbar, "Work stress experienced by the teaching staff of university of the Punjab, Pakistan: antecedents and consequences," International Journal of Business and Social Science, vol. 2, no. 8, pp. 202-210, 2011.

[7] S. Z. Salilih and A. A. Abajobir, "Work-related stress and associated factors among nurses working in Public Hospitals of Addis Ababa, Ethiopia: a cross-sectional study," Workplace Health and Safety, vol. 62, no. 8, pp. 326-332, 2014.

[8] T. Pisljar, T. van der Lippe, and L. den Dulk, "Health among hospital employees in Europe: a cross-national study of the impact of work stress and work control," Social Science and Medicine, vol. 72, no. 6, pp. 899-906, 2011.

[9] F. Demir, P. Ay, M. Erbaş, M. Özdil, and E. Yaşar, "İstanbul'da bir eğitim hastanesinde çalışan tıpta uzmanlık öğrencileri nde depresyon yaygınlığı ve ilişkili etkenler," Turk Psikiyatri Derg, vol. 18, pp. 31-37, 2007.

[10] B. A. Al-Omar, "Sources of work-stress among hospital-staff at the Saudi MOH," Journal of King Abdulaziz UniversityEconomics and Administration, vol. 17, no. 1, 2003.

[11] I. L. Petterson, B. B. Arnetz, J. E. Arnetz, and L. G. H“orte, "Work environment, skills utilization and health of Swedish nurses-results from a national questionnaire study," Psychotherapy and Psychosomatization, vol. 64, no. 1, pp. 20-31, 1995.

[12] D. Rees and C. L. Cooper, "Occupational stress in health service workers in the UK," Stress Medicine, vol. 8, no. 2, pp. 79-90, 1992.

[13] S. Cartwright and C. L. Cooper, "Public policy and occupational health psychology in Europe," Journal of Occupational Health Psychology, vol. 1, no. 4, pp. 349-361, 1996.

[14] O. Familoni, "An overview of stress in medical practice," African Health Sciences, vol. 8, no. 1, pp. 6-7, 2008.

[15] L. Gregov, A. Kovačević, and A. Slišković, "Stress among Croatian physicians: comparison between physicians working in emergency medical service and health centers: pilot study," Croatian Medical Journal, vol. 52, no. 1, pp. 8-15, 2011.

[16] S. Emmett, "Why lawyers need resilience," Bulletin (Law Society of South Australia), vol. 35, no. 3, p. 31, 2013.

[17] J. E. Bower and S. C. Segerstrom, "Stress management, finding benefit, and immune function: positive mechanisms for intervention effects on physiology," Journal of Psychosomatic Research, vol. 56, no. 1, pp. 9-11, 2004.

[18] W. Linden, J. W. Lenz, and A. H. Con, "Individualized stress management for primary hypertension: a randomized trial," Archives of Internal Medicine, vol. 161, no. 8, pp. 1071-1080, 2001.
[19] K. A. McGonagle and R. C. Kessler, "Chronic stress, acute stress, and depressive symptoms," American Journal of Community Psychology, vol. 18, no. 5, pp. 681-706, 1990.

[20] B. K. Tarnini and B. Kord, "Burnout components as Predictors of job and life satisfaction of university employees," Indian Journal of Industrial Relations, vol. 47, no. 1, pp. 126-137, 2011.

[21] L. Groves and R. Hinton, Inclusive Aid: Changing Power and Relationships in International Development, Routledge, Abingdon, UK, 2013.

[22] S. Kushwaha, "Stress management at workplace," Global Journal of Finance and Management, vol. 6, no. 5, pp. 469472, 2014.

[23] D. Saha, R. Sinha, and K. Bhavsar, "Understanding job stress among healthcare staff," Online Journal of Health and Allied Sciences, vol. 10, no. 1, p. 6, 2011.

[24] E. A. Willems, Stress among Social Work Professionals in Mental Health Care Settings, St. Catherine University, Saint Paul, MN, USA, 2014.

[25] A. Salam, M. Abu-Helalah, S. L. Jorissen, K. Niaz, A. Mansour, and A. Al Qarni, "Job stress and job satisfaction among health care professionals," European Scientific Journal, vol. 10, no. 32, 2014.

[26] P. P. Kane, "Stress causing psychosomatic illness among nurses," Indian Journal of Occupational and Environmental Medicine, vol. 13, no. 1, pp. 28-32, 2009.

[27] M. R. Visser, E. M. Smets, F. J. Oort, and H. C. de Haes, "Stress, satisfaction and burnout among Dutch medical specialists," Canadian Medical Association Journal, vol. 168, no. 3, pp. 271-275, 2003.

[28] A.-S. Nyssen, I. Hansez, P. Baele, M. Lamy, and V. De Keyser, "Occupational stress and burnout in anaesthesia," British Journal of Anaesthesia, vol. 90, no. 3, pp. 333-337, 2003.

[29] A. M. Mosadeghrad, "Occupational stress and turnover intention: implications for nursing management," International Journal of Health Policy and Management, vol. 1, no. 2, pp. 169-176, 2013.

[30] N. Ogińska-Bulik, "Occupational stress and its consequences in healthcare professionals: the role of type D personality," International Journal of Occupational Medicine and Environmental Health, vol. 19, no. 2, pp. 113-122, 2006.

[31] H. Sveinsdottir, P. Biering, and A. Ramel, "Occupational stress, job satisfaction, and working environment among Icelandic nurses: a cross-sectional questionnaire survey," International Journal of Nursing Studies, vol. 43, no. 7 , pp. 875-889, 2006.

[32] S. Sehlen, D. Vordermark, C. Schäfer et al., "Job stress and job satisfaction of physicians, radiographers, nurses and physicists working in radiotherapy: a multicenter analysis by the DEGRO Quality of Life Work Group," Radiation Oncology, vol. 4, no. 1, p. 6, 2009. 


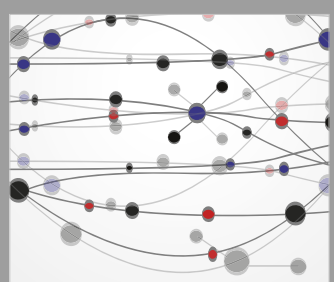

The Scientific World Journal
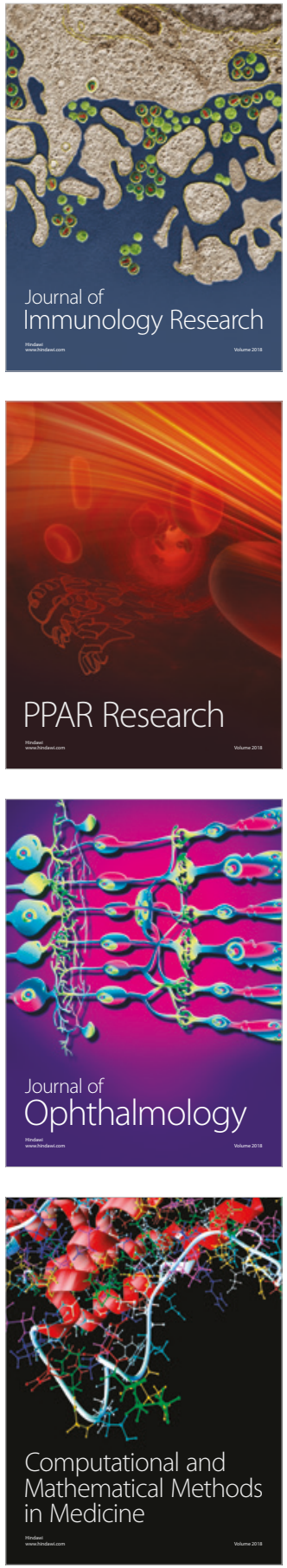

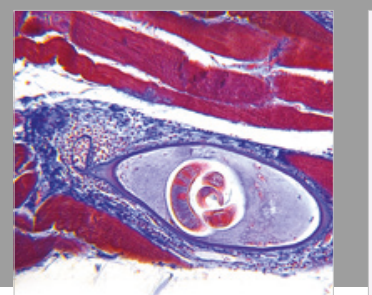

Gastroenterology Research and Practice

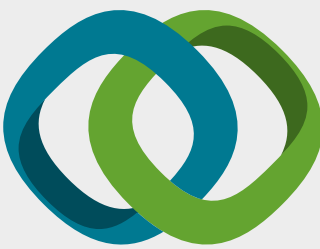

\section{Hindawi}

Submit your manuscripts at

www.hindawi.com
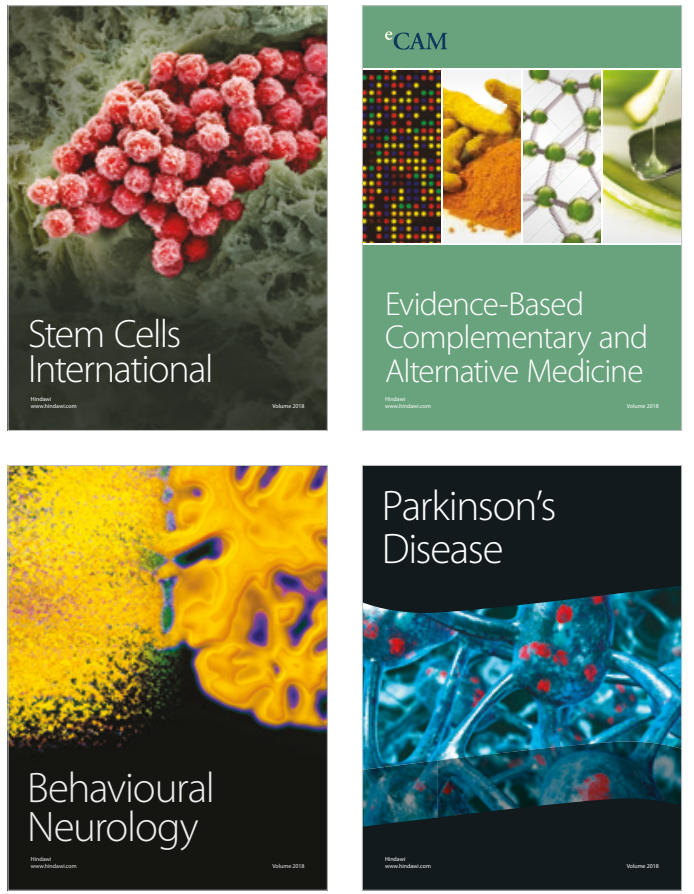

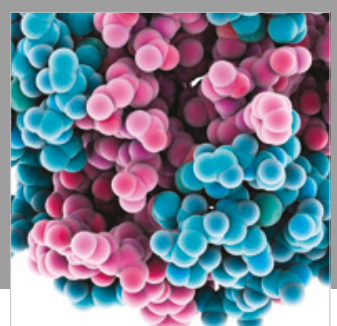

ournal of

Diabetes Research

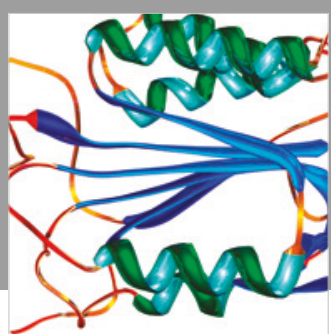

Disease Markers
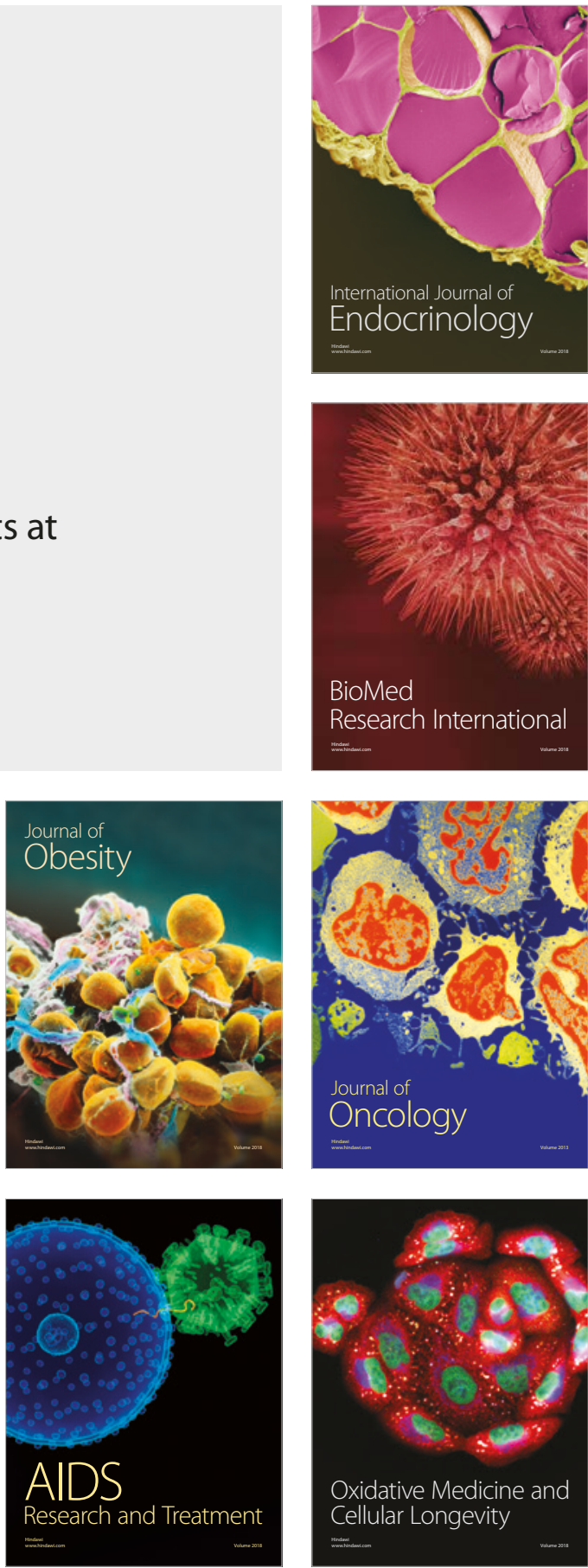